\title{
A severe and complicated case of recurrent Clostridium difficile colitis in a 27- month-old boy: A rare entity in young children
}

\author{
Uzma Rani $^{1}$, Aamer Imdad ${ }^{2}$ and Maribeth Nicholson ${ }^{2 *}$ \\ ${ }^{1}$ Division of Nephrology and Hypertension, Vanderbilt University, Nashville, TN, USA \\ ${ }^{2}$ Division of Pediatric Gastroenterology, Nutrition and Hepatology, Vanderbilt University, Nashville, TN, USA
}

\begin{abstract}
We present a case of a 27 -month-old boy with severe Clostridium difficile infection complicated by toxic megacolon, rectal prolapse, hypoalbuminemia, and ascites. The patient improved with antibiotics but later presented with recurrent Clostridium difficile colitis. Antibiotic therapy for recurrent Clostridium difficile infection was given and after recovery, fecal microbiota transplantation was performed to prevent further recurrence of disease. The patient did well on follow-up. Severe Clostridium difficile disease is rare in young children and colonization is common.
\end{abstract}

\section{Case report}

A 27-month-old male patient presented to the pediatric emergency department with complaints of diarrhea and vomiting for 4 days. He had large, watery, non-bloody, non-mucoid stools with a frequency of 10-12 episodes/day. The patient was reported to be febrile at home with a temperature of $102^{\circ} \mathrm{F}$. His oral intake was significantly decreased, and he had minimal urine output. Past medical history included a recent hospitalization for respiratory syncytial virus bronchiolitis for 3 days and the use of antibiotics during this stay. On physical examination, the patient appeared ill and fussy with dry mucous membranes. He was tachycardiac on initial evaluation with a heart rate of 156 beats/min. His abdominal examination showed a distended but soft abdomen with mild diffuse tenderness to palpation. His initial laboratory studies were significant for a white blood count of 21.8 cells per microliter $(\mu \mathrm{L})$, sodium of $122 \mathrm{mEq} / \mathrm{L}$, potassium of $5.2 \mathrm{mEq} / \mathrm{L}$, and a chloride of $95 \mathrm{mEq} / \mathrm{L}$. He was also hypoalbuminemic with an albumin of $2.6 \mathrm{gm} /$ $\mathrm{dL}$. The patient was admitted to the hospital for supportive care and correction of electrolyte imbalances.

Stool studies were positive for Clostridium difficile (C. difficile) via DNA amplification testing and the patient was started on oral metronidazole, which was later switched to the intravenous route due to vomiting. Oral vancomycin was later added due to persistent symptoms. The patient developed peripheral edema with pleural effusion and ascites. On repeat laboratory evaluation, his albumin and total protein both were low at $1.6 \mathrm{~g} / \mathrm{dl}$ and $3.5 \mathrm{gm} / \mathrm{dl}$ respectively. The patient underwent therapeutic paracentesis along with an infusion of $25 \%$ albumin. His upper gastrointestinal endoscopy revealed esophagitis, gastritis and a duodenal ulcer. Flexible sigmoidoscopy showed bowel wall edema and pseudomembranous colitis (Figure 1). Colonic biopsies demonstrated fragments of edematous colonic mucosa and fragments of hyperplastic-appearing colonic mucosa with abundant associated mucin; negative for active inflammation or granuloma. An abdominal x-ray revealed dilated bowel loops concerning for toxic megacolon (Figure 2) which was confirmed on subsequent CT scan of abdomen. Meanwhile, the patient developed rectal prolapse. Toxic megacolon was treated conservatively with nothing per oral, intravenous antibiotics and total parental nutrition. No surgical intervention was required. The patient was continued on antibiotics and total parenteral nutrition for 3 weeks. His condition improved gradually and he was discharged home after completion of antibiotics.

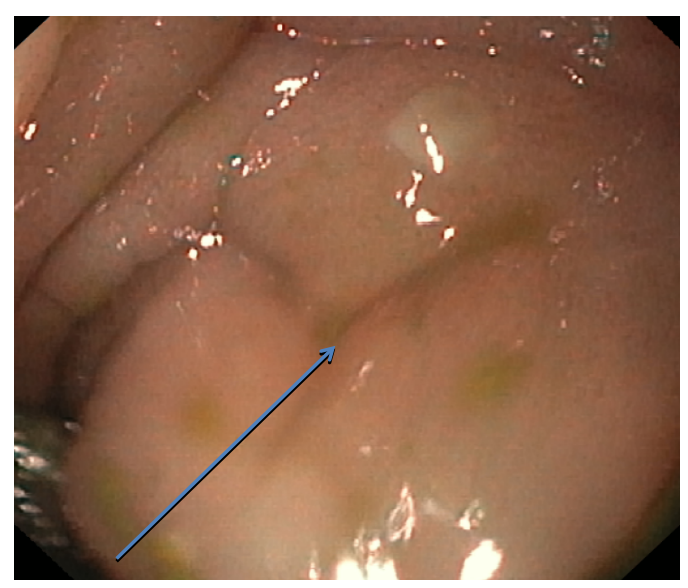

Figure 1. Endoscopic image of pseudo-membranes in colon.

Correspondence to: Dr. Maribeth Nicholson, MD, MPH, Division of Pediatric Gastroenterology, Hepatology, and Nutrition. Monroe Carell Jr. Children's Hospital, Vanderbilt University, 2200 Children's Way, Nashville, TN 37232, USA; Tel: (615)322-7449; Fax: (615)936-8128, E-mail: maribeth.r.nicholson@ vanderbilt.edu

Uzma Rani, MBBS, Vanderbilt University, 2200 Children's Way, Nashville, TN 37232, USA; Tel: (315) 560-9915; uzmamanal@yahoo.com

Received: May 21, 2017; Accepted: May 22, 2017; Published: May 25, 2017 


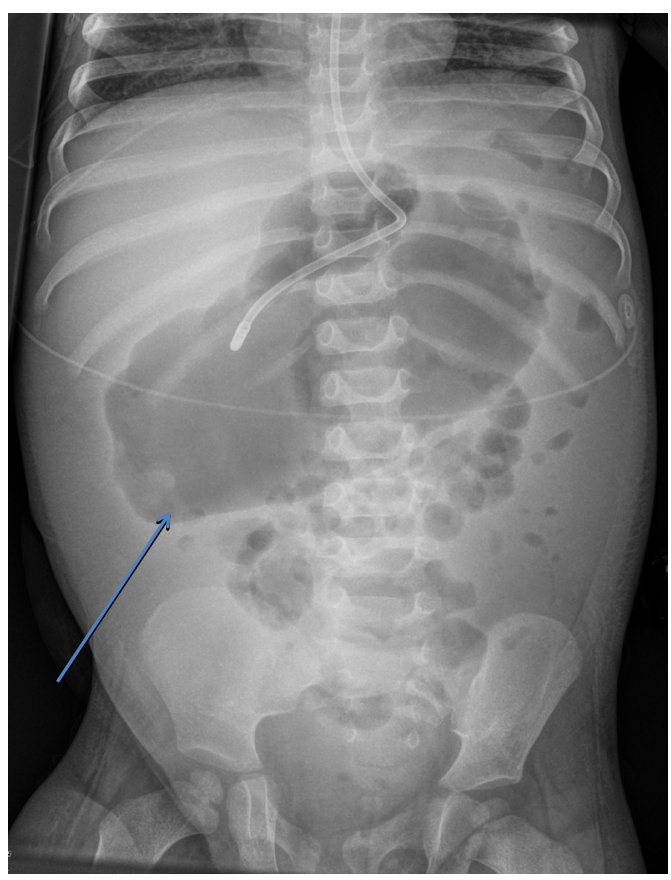

Figure 2. Abdominal radiograph with toxic megacolon.

One week later, the patient again presented with watery, nonbloody diarrhea, accompanied by vomiting, fever and loss of appetite. His stool studies were positive for C.difficile and he was found to have hypoalbuminemia $(2.5 \mathrm{~g} / \mathrm{dl})$ and mild ascites. He was started on intravenous metronidazole and oral Vancomycin to which he responded. As the patient presented with recurrent and complicated CDI, fecal microbial transplantation (FMT) was discussed with his family and was performed when a healthy related donor was identified. The donor was screened for transmissible infections per guidelines [1]. Antibiotics were held approximately 24 hours prior to the procedure. FMT was performed with $50 \mathrm{~g}$ of donor stool homogenized with $100 \mathrm{cc}$ of normal saline and instilled via nasoduodenal tube. The procedure was well tolerated without complication. Post-transplantation, the patient did well with complete resolution of symptoms and no further recurrences on follow-up 2 months post-procedure.

\section{Discussion}

We present a unique case of a young, otherwise healthy child, with severe and recurrent $C$. difficile infection (CDI). The patient had significant morbidity related to CDI and required invasive diagnostic and therapeutic measures. Although symptoms initially responded to supportive measures and oral and IV antibiotics, CDI recurred within a week of hospital discharge. The second episode was also severe and required IV and oral antibiotics. Further recurrence was successfully prevented by FMT.

Severe CDI is rare in infants and young children and asymptomatic carriage is common, with carriage rates as high as $60-70 \%$ [2]. Due to these findings, the American Academy of Pediatrics has recommended limited testing in these young children [3]. In addition, CDI-related complications such as toxic megacolon, sepsis, and colectomy are very rare in young children [4], and there are few reported cases $[5,6]$. Recent analyses of hospital data from two different centers reported less than a $2 \%$ incidence of toxic megacolon and sepsis [4].

The treatment of CDI includes the discontinuation of the potentially causative agent, supportive care such as hydration and if necessary, the use of pharmacological agents against CD $[7,8]$. The choice of the pharmacological agent depends on the severity of the disease [9]. Conventional pharmacotherapy includes metronidazole as a first choice drug, but if symptoms persist, tapered or pulsed oral vancomycin can be added [7]. A relatively new drug option include fidaxomicin which is a macrolide antibiotic and works by inhibiting RNA synthesis through its inhibitory effect on DNA-dependent RNA polymerase [10]. This drug has been approved for use in the adult population in the USA. However, its role in treating pediatric CDI is still under investigation [8]. A multicenter open-label, phase 2 clinical trial investigating the safety, efficacy, and pharmacokinetics of fidaxomicin in the pediatrics population (age 6 months to 18 years) has been recently completed [11]. (NCT01591863) Another ongoing multicenter, randomized, single-blind, phase 3 clinical trial is comparing the safety and efficacy of fidaxomicin and vancomycin for the treatment of CDI in the pediatric population (SUNSHINE) [12]. (NCT02218372) Nitazoxanide and rifaximin also contain antimicrobial activity against $\mathrm{CD}$ but sufficient data is lacking in children [8].

Only recently have we begun to understand the risk of recurrent CDI in children with reported recurrence rates of $20-31 \%$ [13-16]. The risk factors for recurrence of CDI in children include recent hospitalization, malignancy, and recent surgery, the use of the acid blocking and immunosuppressant agents and antibiotic use $[7,13]$. Recurrent CDI can also be treated with supportive care and pharmacotherapy such as metronidazole and vancomycin [9]. The efficacy of medical therapy to prevent further recurrence of CDI is limited and most of the data is from adult studies. The concept of restoration of colonic microbiota and improvement in 'colonization resistance' through probiotic treatment and FMT has shown promising results in some case reports in children $[17,18]$. Immunotherapy with monoclonal antibodies against CD toxin has also shown positive results in adults [19]. Very rarely, colectomy is used as a treatment for the complicated and life-threatening cases of CDI [7].

FMT has been used in the adult population to prevent the recurrence of CDI and is reported to be effective in up to $90 \%$ of patients [1]. Walia et al. reported two pediatric cases successfully treated with FMT for recurrent CDI [20]. A recent case series reported 10 pediatric cases that were successfully treated with FMT. Median age of the treated patients was 5.4 years and four of the patients were $<3$ years of age [18]. The selection of the recipient for FMT is based on clinical judgment, while the donor is selected after extensive screening for communicable diseases [21]. The preparation for transplantation includes dilution via water or normal saline to create a stool suspension [21,22]. Selection of the methods for administration depends on clinical scenario, available resources, and patient preference and commonly used routes include nasogastric and nasoduodenal or nasojejunal tubes, gastroscopy, enemas and colonoscopic administration [17,21]. Resolution of CDI symptoms and absence of recurrence within 8 weeks is considered as successful FMT [21]. All reported data and our case, where FMT was used to prevent the recurrence of CDI in a complicated CDI, further authenticate the safety and effectiveness of FMT use in children.

Our patient was treated with FMT based on his severe and recurrent disease and had a successful response. The patient has done well since the transplant and no side effects have been reported on 2-month follow-up. This case illustrates that severe and recurrent CDI may occur in young children; a group classically felt to be without severe manifestations, and further recurrence can be safely and effectively prevented with FMT. 


\section{References}

1. Brandt LJ, Reddy SS (2011) Fecal microbiota transplantation for recurrent clostridium difficile infection. J Clin Gastroenterol 45 Suppl: S159-167. [Crossref]

2. Jangi S, Lamont JT (2010) Asymptomatic colonization by Clostridium difficile in infants: implications for disease in later life. J Pediatr Gastroenterol Nutr 51: 2-7. [Crossref]

3. Schutze GE, Willoughby RE, Committee on Infectious Diseases, American Academy of Pediatrics (2013) Clostridium difficile infection in infants and children. Pediatrics 131: 196-200. [Crossref]

4. Sammons JS, Toltzis P, Zaoutis TE (2013) Clostridium difficile Infection in children. JAMA Pediatr 167: 567-573. [Crossref]

5. Pokorn M, Radsel A, Cizman M, Jereb M, Karner P, et al. (2008) Severe Clostridium difficile-associated disease in children. Pediatr Infect Dis J 27: 944-946. [Crossref]

6. Angel CA, Green J, Swischuk L, Patel J (2004) Severe ciprofloxacin-associated pseudomembranous colitis in an eight-year-old child. J Pediatr Surg 39: 1590-1592. [Crossref]

7. Borali E, De Giacomo C (2016) Clostridium Difficile Infection in Children: A Review. J Pediatr Gastroenterol Nutr 63: e130-130e140. [Crossref]

8. Schutze GE, Willoughby RE, Committee on Infectious Diseases, American Academy of Pediatrics (2013) Clostridium difficile infection in infants and children. Pediatrics 131: 196-200. [Crossref]

9. Kelly CP, Pothoulakis C, LaMont JT (1994) Clostridium difficile colitis. N Engl J Med 330: 257-262. [Crossref]

10. Lee C, Louie TJ, Weiss K, Valiquette L, Gerson M, et al. (2016) Fidaxomicin versus Vancomycin in the Treatment of Clostridium difficile Infection: Canadian Outcomes. Can J Infect Dis Med Microbiol 2016: 8048757.

11. NCT01591863 (2012) Safety, Tolerability, and Pharmacokinetics of Fidaxomicin in Pediatric Subjects With Clostridium Difficile-associated Diarrhea (CDAD). clinicaltrials.gov

12. NCT02218372 (2014) A Study to Investigate the Safety and Efficacy of Fidaxomicin
(Oral Suspension or Tablets) and Vancomycin (Oral Liquid or Capsules) in Pediatric Subjects With Clostridium Difficile-associated Diarrhea (CDAD) (SUNSHINE). clinicaltrials.gov

13. Nicholson MR, Thomsen IP, Slaughter JC, Creech CB, Edwards KM (2015) Novel risk factors for recurrent Clostridium difficile infection in children. J Pediatr Gastroenterol Nutr 60: 18-22. [Crossref]

14. Khanna S, Baddour LM, Huskins WC, Kammer PP, Faubion WA, et al. (2013) The epidemiology of Clostridium difficile infection in children: a population-based study. Clin Infect Dis 56: 1401-1406. [Crossref]

15. Morinville V, McDonald J (2005) Clostridium difficile-associated diarrhea in 200 Canadian children. Can J Gastroenterol 19: 497-501. [Crossref]

16. Marsh JW, Arora R, Schlackman JL, Shutt KA, Curry SR, et al. (2012) Association of relapse of Clostridium difficile disease with BI/NAP1/027. J Clin Microbiol 50: 40784082. [Crossref]

17. Biller JA, Katz AJ, Flores AF, Buie TM, Gorbach SL (1995) Treatment of recurrent Clostridium difficile colitis with Lactobacillus GG. J Pediatr Gastroenterol Nutr 21: 224-226. [Crossref]

18. Kronman MP, Nielson HJ, Adler AL, Giefer MJ, Wahbeh G, et al. (2015) Fecal microbiota transplantation via nasogastric tube for recurrent clostridium difficile infection in pediatric patients. J Pediatr Gastroenterol Nutr 60: 23-26. [Crossref]

19. Lowy I, Molrine DC, Leav BA, Leav BA, Blair BM, et al. (2010) Treatment with monoclonal antibodies against Clostridium difficile toxins. N Engl J Med 362: 197-205.

20. Walia R, Garg S, Song Y, Girotra M, Cuffari C, et al. (2014) Efficacy of fecal microbiota transplantation in 2 children with recurrent Clostridium difficile infection and its impact on their growth and gut microbiome. J Pediatr Gastroenterol Nutr 59: 565-570. [Crossref]

21. Bakken JS, Borody T, Brandt LJ, Brill JV, Demarco DC, et al. (2011) Treating Clostridium difficile infection with fecal microbiota transplantation. Clin Gastroenterol Hepatol 9: 1044-1049. [Crossref]

22. Aroniadis OC, Brandt LJ (2013) Fecal microbiota transplantation: past, present and future. Curr Opin Gastroenterol 29: 79-84. [Crossref]

Copyright: (C2017 Rani U. This is an open-access article distributed under the terms of the Creative Commons Attribution License, which permits unrestricted use, distribution, and reproduction in any medium, provided the original author and source are credited. 